\title{
Homotransplantation of the lung in dogs, with special reference to the circulation system in the transplant
}

\author{
T. J. OTTO AND M. TRENKNER \\ From the Department of Thoracic and Cardiac Surgery, Institute of Tuberculosis, Warsaw, Poland
}

The problem of substituting injured or diseased organs for healthy ones has been intriguing scientists for years. Animal experiments and subsequently successful transplantations of human kidneys in the fifties proved that the transplantation of organs is in reality possible, but complete success depends on the further understanding of immunological processes occurring in the recipient in response to the implanted foreign tissue. Some means of suppressing these processes and stopping the rejection of the transplanted lung must be found.

The problem of transplanting the lung seems to be of particular practical interest, since the human lung is an organ that is often removed surgically, and in recent years the indications for such a procedure have increased. Quite often, however, the low respiratory reserve of the patient excludes the possibility of operation. It seems that in many of these cases the transplantation of a lung might solve the problem of respiratory deficiency and save the patient's life.

The first experiments published were those of Juvenelle, Citret, Wiles, and Stewart (1951), who achieved survival after reimplanting the lung in dogs. In 1947, Demichow (1963) had experimented by transplanting the lobe of a dog's lung, but only recently have his experiments become known.

Neptune, Weller, and Bailey (1953) had a year's survival after reimplantation. Hardin and Kittle (1954), after successfully transplanting the left lung, performed within a few days pneumonectomy on the opposite side and achieved survival for a further few days, thus proving that the transplanted lung was temporarily functioning sufficiently.

These experiments indicated that the transplantation of animals' lungs is feasible, and that after reimplantation long-term survivals are within reach. Homotransplantation, however, has proved more difficult, due to the immunological

${ }^{1}$ Instytut Gruźlicy, Warszawa, ul. Płocka 26, Poland reaction that occurs, giving as a final result rejection of the transplanted lung. This phenomenon stimulated attempts to find a means of stopping $z$ the rejection mechanism. Radiotherapy, vaccination with small doses of antigen obtained from donor's tissues, corticoids, cross-circulation of the donor and recipient, and several pharmacological drugs have been tried (Neptune et al., 1953; Parsa, Faber, Staub, and Beattie, 1964 ; Gago, ? Delgado, Archer, Schoenfeld, Ranniger, Nigro, and Adams, 1964 ; Gago, Zajtchuk, Nigro, and Adams, 1965). So far the best results have been obtained by using the last of these ways. Blumenstock, Collins, Hechtman, Thomas, and Ferrebee (1962) and later de Bono and Brock (1964) observed long-term survival after the administration of methotrexate. Hardy, Eraslan, Dalton, $\frac{3}{\overrightarrow{ }}$ Alican, and Turner (1963a) achieved good results with azathioprine (Imuran). The immunopressive action of this drug has also been proved by its successful use after the transplantation of human $\underset{\times}{\otimes}$ kidneys.

The solution of immunological problems, however important, is not the only barrier to successful homotransplantation in animals or human beings. $₹$ Although Hardy, Webb, Dalton, and Walker $\mathrm{O}$ (1963b) and Magovern and Yates (1964), after numerous experiments on animals, attempted lungo transplantation in man and achieved partial success, this procedure is not as yet reliable enough for general use. The rate of survival in animalsn is still not satisfactory, and complications are numerous.

The lung is an organ of complicated function, and the mere fact that the transplanted lung is? not being rejected does not necessarily mean thates in longer terms it will remain of use to the recipient. Some impressive studies were carried outo by several authors in order to establish the func- $-\frac{\mathbb{D}^{\circ}}{}$ tion of the reimplanted or transplanted lung, and $\stackrel{?}{\mathrm{D}}$ although results obtained were varied, it seems that the transplanted lung retains a sufficient 
degree of function to participate in oxygenation and elimination of carbon dioxide, thus being of value to the recipient (Yeh, Ellison, and Ellison, 1962 ; Bücherl, Nasseri, and Prondzynski, 1964a ; Bücherl, Eisele, Kirsch, Köhn, and Nasseri, $1964 \mathrm{~b}$; Davies, Rosser, and West, 1965 ; Faber, Pevsner, Pedreira, and Beattie, 1965).

The experiments presented in this paper began at the beginning of 1965 , when some of the problems of transplantation had already been solved. They were meant primarily to master various techniques concerned with transplanting the homologous lung and handling the homograft. However, particular interest was focused on the circulation system in the transplanted lung, as in our opinion several points in this respect were not sufficiently clear. We decided on the transplantation procedure rather than the reimplantation.

\section{MATERIAL AND METHODS}

Experiments were performed on 46 mongrel dogs of both sexes. The weight of these animals ranged from 5 to $15 \mathrm{~kg}$., and the age from 1.5 to 8 years. Twentytwo dogs served as donors, 24 as recipients. In two instances one donor supplied both lungs for two recipients. Donors and recipients were not related. Twenty-four transplantations of the lung were carried out-21 of the left lung and three of the right. Directly after the transplantation had been completed, the function of the transplanted lung was estimated, and microscopic observations of the blood circulation in the pulmonary tissue were carried out. After the operation short-term survivals were aimed at, and subsequently the dogs were anaesthetized again. In some of them angiography was carried out at various times after the initial procedure; others were submitted for rethoracotomy, during which direct microscopic observations were made, and in some oxygen saturations were investigated. Subsequently the animals were sacrificed. All animals killed and those which died from post-operative complications were submitted to necropsy. Specimens of both lungs with the main pulmonary artery and the left atrium were examined radiologically with the use of contrast medium, and subsequently histological examinations of both lungs, vessels, and bronchi were carried out.

ANAESTHESIA The dogs were anaesthetized by administering inactin intravenously, and they were then intubated. Controlled respiration was performed. Further anaesthesia was maintained with small doses of inactin, and sufficient relaxation was achieved by hyperventilation. All donors were heparinized (4 mg./kg. body weight) and had the femoral artery exposed to be bled after pneumonectomy, in order to deliver the blood for recipients and for other experiments.
OPERATION Posterior thoracotomy through the fourth or fifth intercostal space was performed in both donors and recipients. Pneumonectomy in donors was performed as a rule intrapericardially, and a narrow margin of the left atrium was excised around orifices of pulmonary veins. The pulmonary artery was severed as close to the main pulmonary artery as possible, and the distal end of the artery was left unclamped. The main bronchus was isolated, care being taken not to damage the bronchial arteries and not to ligate their distal ends. The bronchus was cut relatively close to the trachea. In later experiments this was altered and only a short bronchial stump was left with the transplant.

Pneumonectomy in recipients was in 10 cases intrapericardial, in the remaining 14 extrapericardial. With the former technique Satynsky's clamp was placed on the left atrium in such a way that when the pulmonary veins were severed a sufficient margin of the atrial wall was left above the clamp, thus enabling subsequent anastomosis. When an extrapericardial procedure was used the veins were ligated separately. The pulmonary artery was clamped with the Blalock clamp and cut off close to its distal branches, so that a relatively long stump was left above the clamp. The bronchus was isolated, clamped, and severed quite far from the trachea, but before suturing the donor's lung the clamped part was cut off and the length of the stump used for anastomosis was about $1.5 \mathrm{~cm}$.

PREPARATION OF THE TRANSPlant Three different treatments of the transplanted lung were used. In eight the collected lung was left covered with wet gauze until the time of implantation, but otherwise unprepared.

In eight the lung was inflated with oxygen and a syringe was attached to the pulmonary artery and the vascular system was perfused with macrodex, with heparin added under very low pressure, until clear fluid was pouring out from the veins and the lung surface became evenly pale-grey in colour. Afterwards the lung was kept inflated in the bowl filled with macrodex. The temperature of the fluid was from $5^{\circ}$ to $10^{\circ} \mathrm{C}$.

In eight cases the transplantation procedure was started by first performing pneumonectomy on the recipient; subsequently the donor's lung was removed and immediately transplanted.

SUTURING THE GRAFT Venous anastomosis was performed. The clamp occluding the atrium was removed, and free retrograde blood flow was permitted until the arterial anastomosis had been completed. In 10 instances the atrial margin of the transplanted lung was sutured directly to the atrial margin of the recipient, in 14 to the reduced left appendage. The pulmonary artery was anastomosed end to end. Vascular anastomoses were carried out with everting continuous sutures of 00000 silk (Figs 1 and 2). 

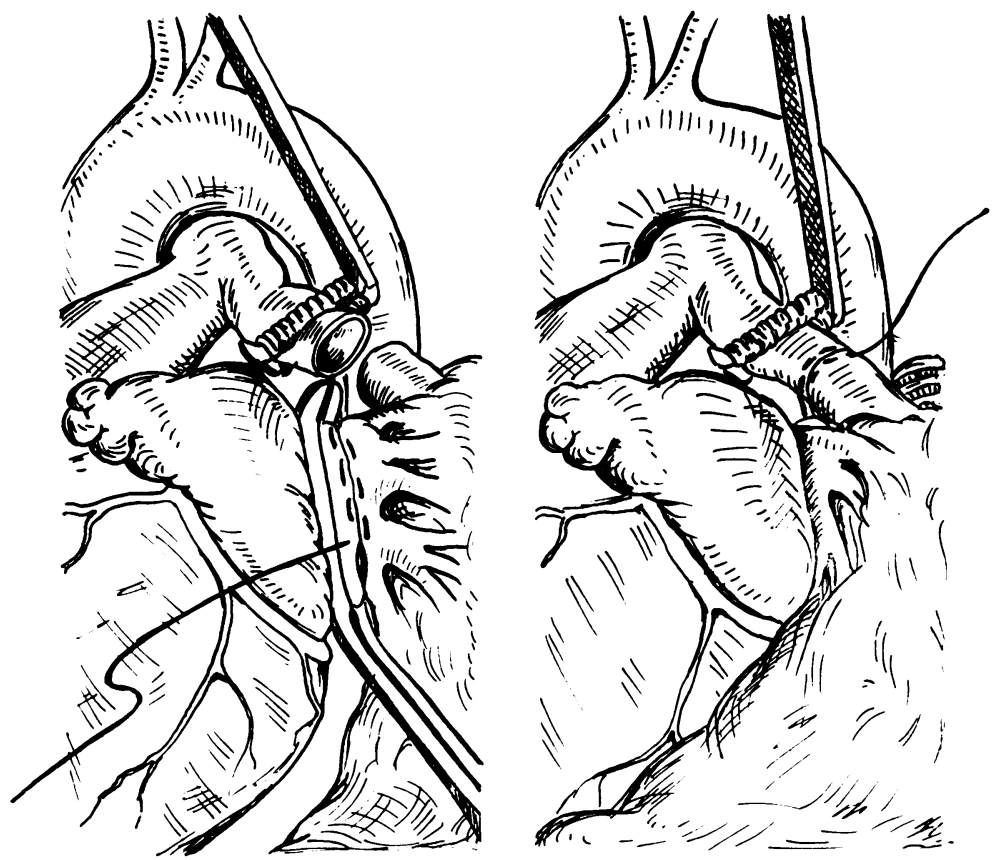

FIG. 1. Transplantation of left lung: (left) venous anastomosis-atrial cuff of donor's lung sutured to atrium of recipient ; (right) arterial anastomosis ; good approach to recipient's pulmonary artery on the whole length is visible.

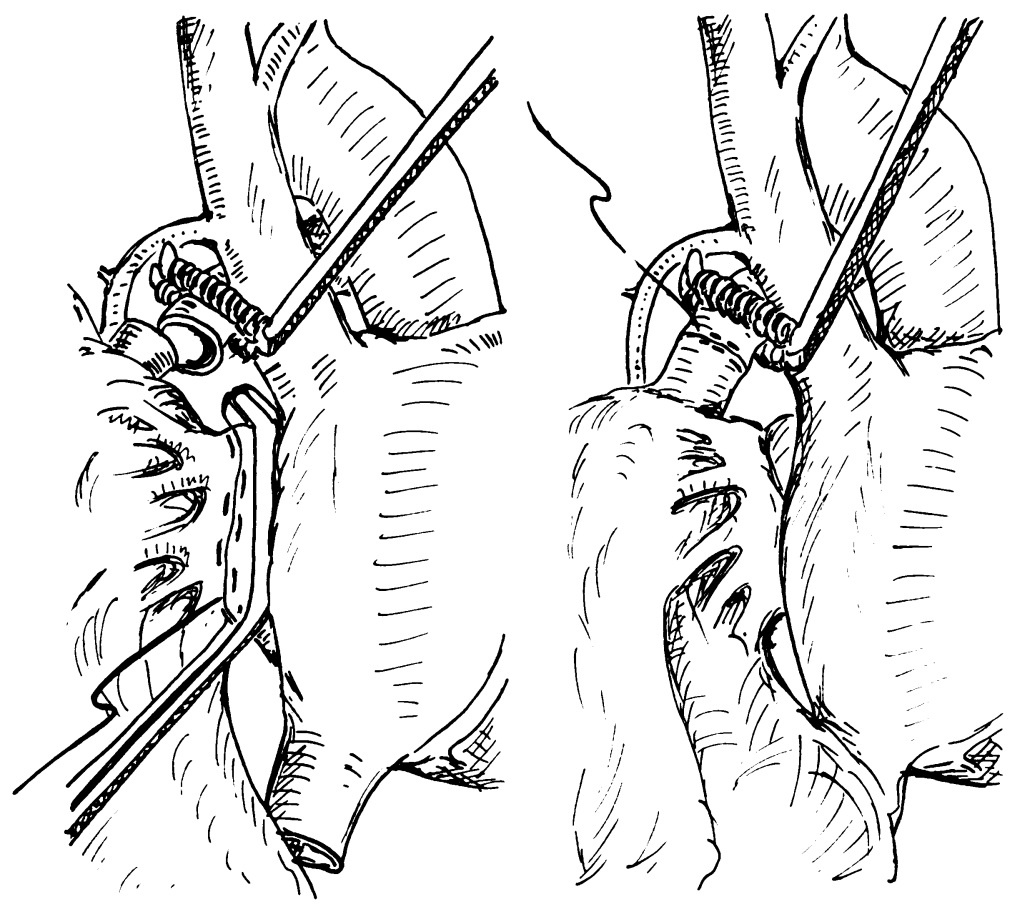

FIG. 2. Transplantation of right lung; (left) venous anastomosis-right atrium seen on the first plane makes the anastomosis with the narrow margin of the left atrium very difficult; (right) arterial anastomosis-only a very short part of the recipient's pulmonary artery is seen beyond the superior vena cava. 
The bronchi were anastomosed end to end with single stitches of 000 or 0000 silk. Once all the anastomoses had been completed the lung was inflated and microscopic observations of the lung surface were carried out. The stereoscopic microscope was used and the best enlargement was found to be $\times 100$.

Afterwards Satynsky's clamp was placed on the venous anastomoses and blood samples were taken below the clamp-that is, from the left atrium and above it-from the orifices of the veins of the transplanted lung. Samples were also taken from the pulmonary artery. All collected samples were examined for oxygen saturation. When all the investigations had been completed a single tube was inserted into the pleural space and the chest was closed in layers.

POST-OPERATIVE CARE After the surgical procedure had been completed the dogs were suspended in hammocks in natural feet-down position. Pleural suction was maintained on an average of 24 hours. Care was taken not to let the animals suffer unnecessarily, and doses of pethidine were administered. All the dogs were heparinized, 1.5 to $2.0 \mathrm{mg} . / \mathrm{kg}$. body weight. Penicillin and streptomycin were given every 12 hours. Dogs intended for a few days' survival were given hydrocortisone. All the dogs were attended to within the first 24 hours constantly and later two-hourly.

INVESTIGATIONS IN THE POST-OPERATIVE PERIOD Five dogs were anaesthetized after 24, 48, 60, 82, and 116 hours; a catheter was inserted into the pulmonary artery and angiography was carried out (Fig. 3).

Seven dogs were submitted for rethoracotomy between 8 and 116 hours after the initial procedure. Microscopic observations of the circulation in precapillary vessels and direct estimation of the function of the transplanted lung were carried out.

NECROPSY All animals were ultimately submitted for necropsy. Both lungs, together with the main pulmonary artery and the left atrium, were removed. The syringe was attached to the pulmonary artery or left atrium, contrast medium was injected under low pressure, and radiographs were taken. These enabled estimation not only of the patency of the arterial or venous anastomoses but also of the whole arterial or venous system of the lungs, including the precapillary vessels. All the specimens were subsequently examined histologically (Figs 4 and 5).

\section{RESULTS}

The surgical results of the transplantation were satisfactory. The venous anastomosis, which is the most difficult, was in all but the first two dogs efficient. The direct anastomosis connecting the atrial cuff of the transplanted lung to the atrium

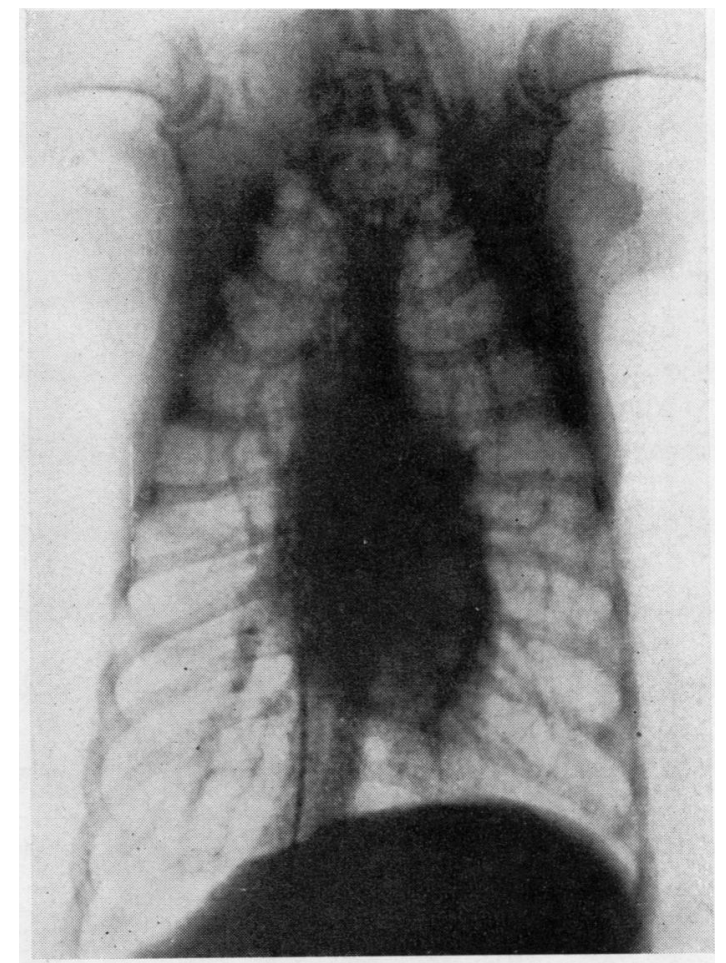

FIG. 3. Angiography performed 24 hours after transplantation of left lung. Catheter introduced and contrast medium injected into pulmonary artery.

is more physiological, but the anastomosis of the cuff to the incised appendage functioned equally well. The latter is easier and quicker to do and it 'elongates' the hilum of the lung, thus enabling easier manœuvres when other anastomoses are done.

The venous anastomosis on the right side was more difficult, but when the interatrial groove was properly developed a sufficient surface of the left atrium was approachable to achieve tight and patent anastomoses.

The patency and function of the venous anastomosis in longer terms was estimated by rethoracotomy, radiography, and necropsy. It was found that in two cases the venous anastomosis was completely occluded by thrombus, and in another two partly occluded, so that only one pulmonary vein in the transplanted lung was functioning. These complications were encountered in two dogs submitted for rethoracotomy after surviving 48 and 120 hours after transplantation, and at necropsy on two dogs which died four and 55 hours after 
FIG. 5

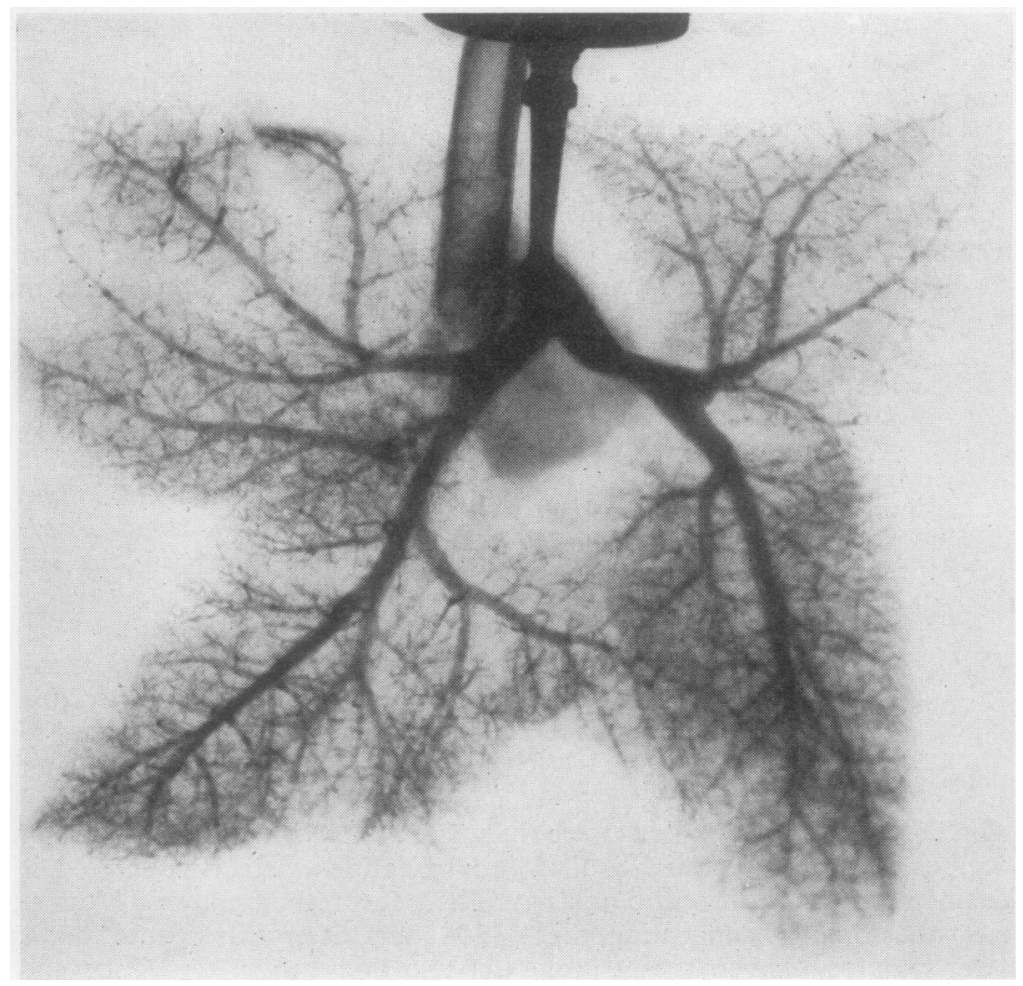






FIG. 4. Specimen from a dog killed three days after transplantation of the left lung. Left atrium and veins injected with contrast medium. Patency of venous system in transplanted lung and broad lumen atrial anastomosis seen.

FIG. 5. Specimen from a dog killed on the third day after transplantation of the left lung. Pulmonary arteries injected with contrast medium. Broad lumen anastomosis and patency of precapillary vessels seen.

FIG. 6. Angiography performed on fifth day after transplantation. Contrast medium does not appear in the transplanted left lung.

FIG. 7. Specimen from a dog which died on the third day after transplantation of the left lung due to thrombosis of the orifices of the inferior and middle lobe veins causing pulmonary haemorrhagic infarction.

FIG. 6

FIG. 7




transplantation. In two of these dogs these complications had previously been diagnosed by angiography (Figs 6 and 7).

The remaining 20 venous anastomoses were functioning well until the time of rethoracotomy or until the death of the animal.

The arterial anastomoses were also satisfactory, although in three cases some bleeding was noticed and additional sutures were required. This resulted in two instances in narrowing of the anastomosis, which in one was resected and resutured, this time with a good result.

On the right side the arterial anastomosis was difficult because of the shortness of a surgically approachable part of the right pulmonary artery (Fig. 2). On that side a better approach for anastomosing the pulmonary artery was obtained by thoracotomy through the fourth intercostal space.

All the arterial anastomoses when examined at the time of rethoracotomy or necropsy were patent, although in three a small thrombus at the suture line was seen, which in one case reduced the lumen considerably (Fig. 8).

Bronchial anastomoses were technically easy to perform. When both lumina were of a different size (which was quite often noticed, despite the fact that the dogs were of more or less the same size) the bronchus with the bigger lumen was reduced in size in the way described by Thompson (1964), that is, by excising a wedge from the bronchial wall and resuturing both margins.

In the first experiments the bronchus of the transplanted lung was left too long and histological examination showed some sloughing of the bronchial mucosa. Therefore in further experiments care was taken to cut and anastomose the bronchus as close to the lung as possible, about $1 \mathrm{~cm}$. from the origin of the upper lobe bronchus.

In all but two cases the bronchial anastomosis was airtight and it was not necessary to cover it with any other tissue. Of the two cases of un-



FIG. 8. Specimen from a dog killed on the fourth day after transplantation of the left lung. Stenosis of the arterial anastomosis is visible. 
T A B L E I

TECHNICAL RESULTS OF TRANSPLANTATION AS ESTIMATED DURING RETHORACOTOMY OR AT NECROPSY

\begin{tabular}{|c|c|c|c|c|}
\hline \multirow{2}{*}{\multicolumn{2}{|c|}{$\begin{array}{l}\text { Condition of } \\
\text { Transplanted } \\
\text { Lung }\end{array}$}} & \multicolumn{3}{|c|}{ No. of Dogs } \\
\hline & & Total & Rethora- & Necropsy \\
\hline \multirow{2}{*}{$\begin{array}{l}\text { Arterial } \\
\text { anastomosis } \\
\text { Venous } \\
\text { anastomosis }\end{array}$} & $\begin{array}{l}\text { Patent } \\
\text { Narrowed } \\
\text { Occluded }\end{array}$ & $\begin{array}{r}20 \\
2 \\
\end{array}$ & $\begin{array}{r}7 \\
1 \\
-\end{array}$ & $\begin{array}{r}13 \\
1 \\
\end{array}$ \\
\hline & $\begin{array}{l}\text { Patent } \\
\text { Narrowed }\end{array}$ & $\overline{18}$ & 6 & $\overline{12}$ \\
\hline \multirow{3}{*}{$\begin{array}{l}\text { Bronchial } \\
\text { anastomosis }\end{array}$} & Occluded & 4 & 2 & 2 \\
\hline & Airtight & 21 & 8 & $1 \overline{3}$ \\
\hline & $\begin{array}{l}\text { Narrowed } \\
\text { Air leak }\end{array}$ & $\overline{1}$ & Z & $\overline{1}$ \\
\hline \multirow{3}{*}{$\underset{\text { tissue }}{\text { Pulmonary }}$} & Well aerated & 16 & 6 & 10 \\
\hline & $\begin{array}{l}\text { Atelectatic } \\
\text { Haemorrhagic }\end{array}$ & 1 & 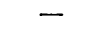 & 1 \\
\hline & infarction & 5 & 2 & 3 \\
\hline
\end{tabular}

satisfactory bronchial anastomosis, one had an air leak which was stopped by an additional stitch; but in the other the air leak was overlooked and resulted in collapse of the lung and subsequently in the death of the animal (Table I).

In lung transplantation the time taken to restore the blood circulation in the transplant is important; therefore we tried to perform the vascular anastomoses as quickly as possible, and in fact when direct transplantation was carried out the time taken from severing the donor's vessels to restoring the full blood circulation was about 45 minutes. When the transplanted lung was perfused before implantation the time was longer, but was always less than two and a half hours.

The immediate function of the transplanted lung, as estimated by direct microscopic observations of the blood flow in precapillary vessels and by measuring the blood oxygen saturation, was good. As is seen from Table II the oxygenating function of the transplanted lung was equal to that of the recipient's own lung. A definite increase in the oxygen saturation of the blood after passing through the transplanted lung was seen (Table II).

Histological observations showed satisfactory blood flow through the precapillary vessels. However, in a number of precapillary vessels open at the time of observation some differences were noticed in the amount of blood passing through them and the time taken for satisfactory circula-

T A B LE II

OXYGEN SATURATION MEASURED WITH ELECTROCOLORIMETER DIRECTLY AFTER TRANSPLANTATION

\begin{tabular}{c|c|c|c}
\hline $\begin{array}{c}\text { No. } \\
\text { of } \\
\text { Dogs }\end{array}$ & $\begin{array}{c}\text { Main } \\
\text { Pulmonary } \\
\text { Artery }\end{array}$ & $\begin{array}{c}\text { Venous Orifices } \\
\text { of Transplanted } \\
\text { Lung }\end{array}$ & Left Atrium \\
\hline 11 & $68.3 \% \pm 1.8 \%$ & $96.7 \% \pm 1.0 \%$ & $97 \% \pm 0.9 \%$ \\
\hline
\end{tabular}

tion to begin. This depended on how the transplant had been prepared. When direct transplantation from animal to animal was carried out the full blood flow was almost immediate. When the transplant had been prepared by perfusion of the vessels with macrodex, equally good blood flow was seen ultimately, but a much longer time elapsed before the circulation appeared. The worst flow was noticed after transplanting the lung which had been left untreated between pneumonectomy in the donor and resuturing in the recipient. Usually such a lung was atelectatic and took a long time to become fully inflated. Until that time the blood flow was meagre, and in some areas it remained so. We consider this method of handling the transplant to be unsatisfactory, mainly due to the need for ventilation under pressure when trying to inflate the atelectatic lung. As our histological investigations showed, this may result in damage to the lung vesicles.

We would like to stress that estimation of the circulation in the transplanted lung by ordinary observation is not reliable. The inflated and ventilated lung may appear to be of 'normal' colour despite the fact that no real circulation exists. We observed this when a narrowed arterial anastomosis obstructed the flow and was subsequently excised and resutured, and also in other cases when the lung was inflated before the arterial anastomoses had been completed.

We began by anastomosing the lung on the venous side, and, once this anastomosis had been completed, we permitted a free, retrograde blood flow. The amount of this flow carried through under very low venous pressure indicated the patency of the circulation in the transplant, and there was a visible relation between this flow and the microscopically observed flow in the precapillary vessels.

The transplantation of two lungs from one donor to two recipients is technically feasible, and we performed this operation in two instances. However, since the portion of left atrium which separates the orifices of the left and right pulmonary veins is very narrow, the atrial cuff of one of the transplanted lungs is inadequate, and this makes anastomosis difficult. Moreover, as the time the lung can safely be kept without irreversible damage is limited, such a procedure would be of greater use if two separate teams were performing two transplantations at the same time.

Out of eight dogs submitted to rethoracotomy the transplanted lung was not aerated in two (48 hours and 120 hours after transplantation). It was big and heavy and resembled the liver. The venous 
anastomosis was occluded by thrombus. In one, the pulmonary artery and its branches were visibly pulsating ; in the other, pulsation of the pulmonary artery was hardly visible, and the branches were already partly thrombosed. All other transplanted lungs were found at the time of rethoracotomy to be well aerated, and good blood circulation was observed. In one, which on histological examination was found to be heavily infiltrated with leucocytes, there were some parts in which the circulation was impaired. Oxygen saturation figures were lower than those obtained immediately after transplantation, but indicated that the function of the transplanted lung had been retained, e.g., dog 35, examined 96 hours after transplantation. The oxygen saturation figures were: pulmonary artery $65 \%$, venous orifices of the transplanted lung $81 \%$, and left atrium $98 \%$.

MORTALITY The mortality in our experiments was high, but it was more usually connected with un-

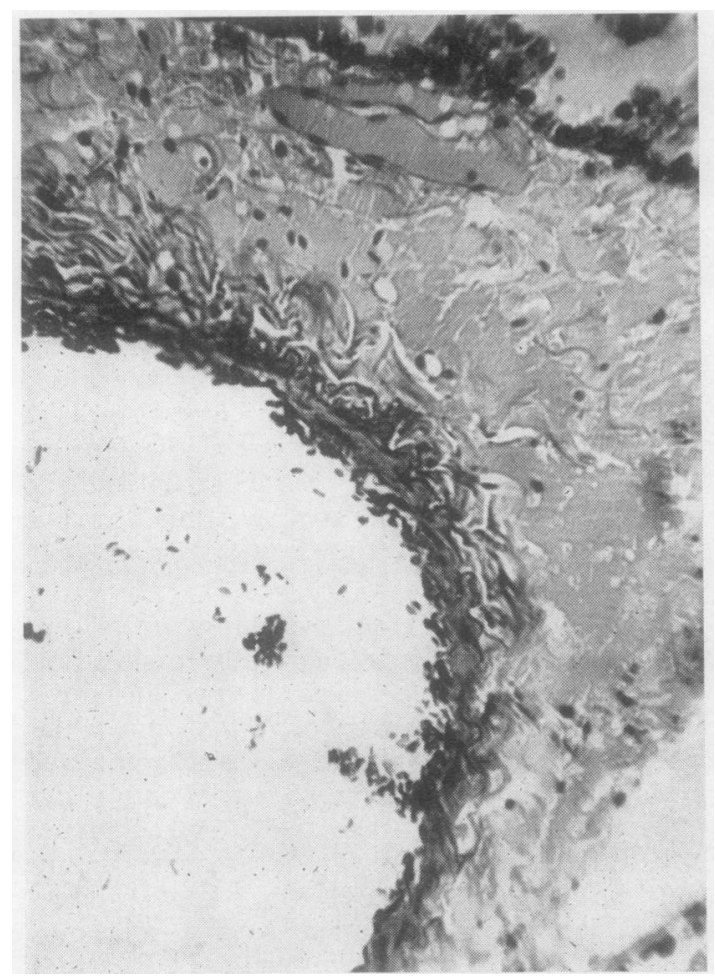

FIG. 9

FIG. 9. The arterial wall in the lung-third day after transplantation. The layers of the arterial wall are oedematous. Typical example of early immunological reaction, $\times 340$.

FIG. 10. Pulmonary tissue of the lung on the fifth day after transplantation. Leucocytic infiltration seen, $\times 340$. successful anaesthesia and post-operative care than with the transplantation-e.g., we lost two dogs due to anaesthetic complications, two because of overdoses of analgesic drugs, and one because of haemorrhage after the administration of heparin. Two dogs died as a result of collapse of their own non-transplanted lungs. (Both these animals lived on transplanted lungs for about 12 hours.) The direct surgical complications were few ; two dogs died as a result of thrombosis of the venous anastomosis of the transplanted lung. The time of death varied between 4 and 60 hours after operation.

HISTOLOGY Histological examinations were not relevant.

Dogs which survived for a few days showed changes which were attributed to immunological reaction. The first change observed, as early as the third or fourth day, was oedema of the capillary walls and round cell infiltration. Later leuco-



FIG. 10 


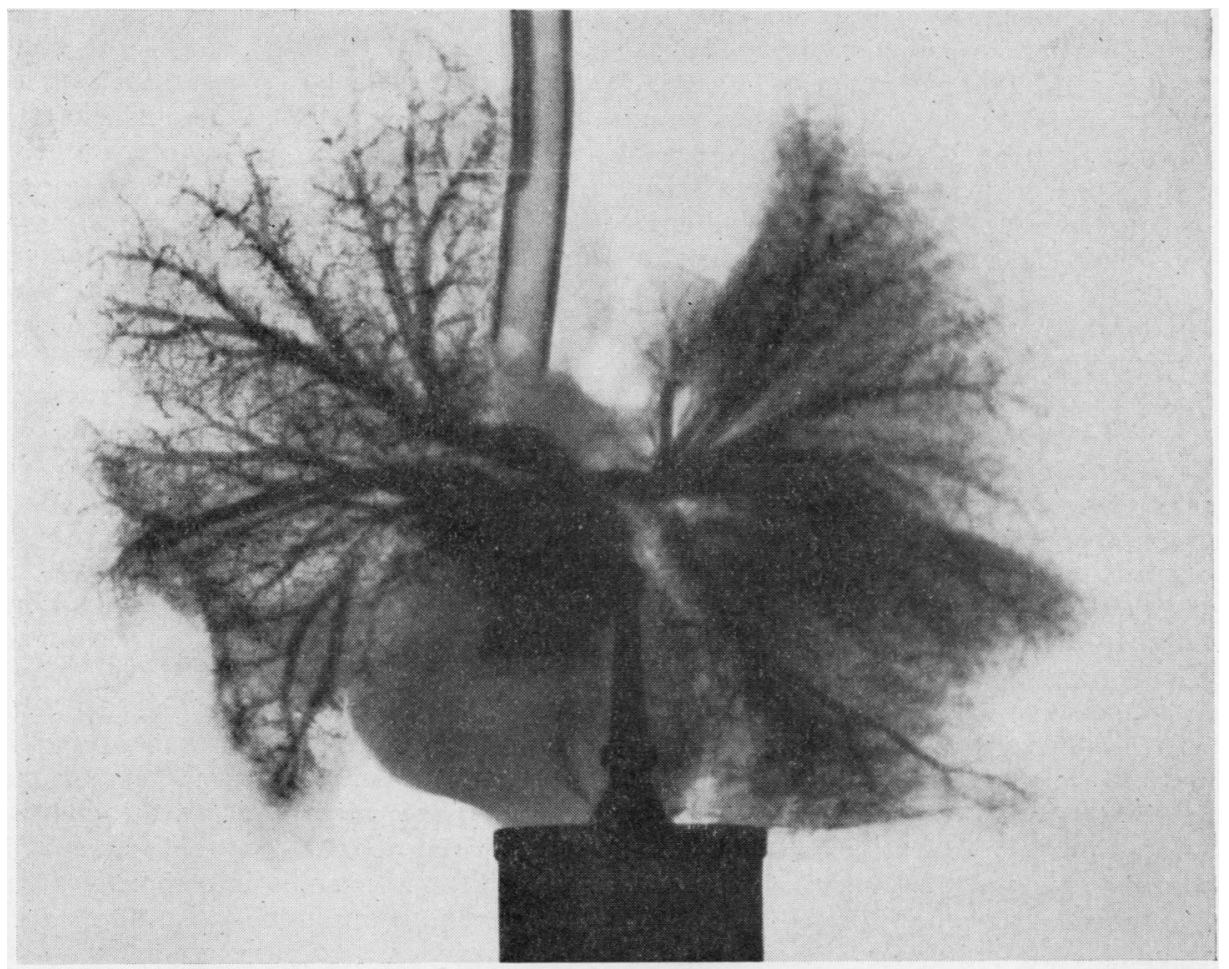

FIG. 11. Specimen from a dog which died on the fourth day after transplantation of the left lung. At necropsy the transplanted lung resembled liver. Injection of contrast medium into the left atrium showed patency of the venous anastomosis and veins in the transplant. An example of pulmonary congestion and haemorrhage, probably due to improper handling of the transplant.

cytic infiltration appeared which in the final stages developed into purulent pneumonia (Figs 9 and 10).

In dogs with thrombosis of the venous anastomosis the typical picture of haemorrhagic pulmonary infarction was seen. The alveolar structure was hardly visible; in some specimens it was not visible, and almost the whole pulmonary tissue was infiltrated with homogenized red cells, which also filled the lumina of the bronchi. In the mass of red cells some leucocytes were observed. A similar picture was seen in one dog in which the venous anastomoses and the whole vascular system of the transplant were found to be patent, but the lung was enlarged and heavy though not to the extent seen after thrombosis of the venous anastomosis (Fig. 11).

As mentioned before, in the first experiments histological examination showed some sloughing of the mucosa lining the proximal part of the main bronchus of the transplant. Even in these specimens the structure of the bronchial wall was otherwise normal. In later experiments, when only a very short bronchial stump was left with the transplant, the histological picture of the bronchial epithelium was normal.

\section{DISCUSSION}

The technical problems concerning transplantation of the lung are relatively easy, but there are some minor points which may influence the proper function of the transplant. The most important is probably the necessity for leaving only a very short bronchial stump with the transplant. The first experiments to suggest the importance of such a policy were those performed by Tobin (1952), who ligated the bronchial arteries in the lung hilum and observed the area of necrosis appearing in the proximal part of the main bronchus. In our first experiments, when the bronchial stump of the transplant was left rather long, as was convenient for technical reasons, sloughing 
of the bronchial mucosa was observed. Similar changes were noticed by other authors (Faber, Kenwell, and Beattie, 1961 ; Neptune et al., 1953 ; Ellis, Grindley, and Edwards, 1951). When some consideration was given to this problem we began to cut the bronchus of the transplant about $1 \mathrm{~cm}$. from its lobar branches so that the anastomosis was close to the lung, and after this we had no problems with sloughing of the mucosa. The explanation of this complication lies in the fact that the bronchial circulation conditioning the state of the bronchial wall and bronchial mucosa is, after ligation of the bronchial arteries or, for that matter, after transplantation, retrograde. In normal conditions about $2 \%$ of systemic blood flows through the bronchial arteries under high systemic pressure, thus providing a sufficient blood supply for the whole bronchial tree. Once the bronchial arteries are severed or ligated, in the hilum, but the pulmonary flow is maintained, retrograde blood flow occurs. The pulmonary blood flows under much lower pressure (in dogs, about $30 \mathrm{~mm}$. $\mathrm{Hg}$ ) from the bronchopulmonary anastomoses into the bronchial arteries. This flow is sufficient to feed the peripheral bronchial tree and the lung tissue but not sufficient to supply the long bronchial stump protruding outside the pulmonary tissue which is the furthest point in reversed bronchial circulation.

The other factor which may negatively influence the collateral bronchial circulation after transplantation is the ligation of the distal ends of the bronchial arteries while the hilum is being dissected. We think that this may lead to thrombosis of the bronchial arteries and that it is better to leave the distal branches open. We never observed any serious bleeding after adopting this policy. In fact, ligation of the structures of the hilum around the main bronchus may have a double effect, because the lymphatic vessels will be ligated as well, leading to oedema of the walls of the alveoli. Therefore, it seems advisable not to ligate the hilum of the transplant too carefully.

The manner in which the transplant is prepared is important if sufficient lung function is to be achieved. It was evident from our experiments that the best results occur after direct transplantation. In transplantation of the human lung this may be difficult to fulfil, and the necessity for preserving the transplant arises. Hence the need to experiment with preserved animals' lungs as well. Blumenstock, Lempert, and Morgado (1965) proved that this may be done in a hyperbaric chamber for as long as $\mathbf{2 4}$ hours without irreversible damage occurring in the lung. In this respect, our experiments were only marginal and the timeo of keeping the transplant was short, but we wouldo을 stress that the lung is best kept inflated and itsक vascular system washed clean of blood, otherwise serious damage to the pulmonary alveoli mayn occur. Improper handling of the transplant may be responsible for pulmonary congestion and haemorrhage of the lung whose vascular anas $\overrightarrow{\vec{\omega}}$ tomoses and vascular bed are patent. We observech one such case (Fig. 11), but it has been noticed more often by others.

Despite all the improvements in transplantation technique, thrombosis of the venous anastomosis is still the most serious complication (Alican and Hardy, 1963 ; Hardy, Eraslan, and Webb, 1964 , Borrie and Lichter, 1964 ; Davies et al., 1965) Even immaculate venous anastomosis may suffer thrombosis. An explanation of this complication was suggested by Huggins (1959), who established the high thromboplastic action of the wall of the pulmonary veins. This suggests that anastomosis of the atrial wall, rather than of the veins, and careful eversion of the margins of the anasto $O$ mosed tissue might prevent thrombosis. Indeed this proved helpful but did not eliminate thes possibility of thrombosis completely. Thrombosis of the venous anastomosis is not always followed by thrombosis of the whole venous system $\stackrel{\mathbb{D}}{\complement}$ which, especially in the early stages, may remain patent (Fig. 12).

Thrombosis begins on the line of the anastomosis. Some authors have tried heparin injection (Yeh et al., 1962; Slim, Yacoubian, Wilson Rubeiz, and Ghandur-Manymneh, 1964). We did̄ this but did not find it successful, which may be due to the dogs' individual differences in reactingo to heparin and difficulties in prolonging the clotting time sufficiently.

One of the essential problems when transplant ing the lung is the influence of denervation of the transplant on its function. Many authors (Blumenstock et al., 1962; Alican and Hardy, 1963 .0. Bücherl et al., 1964a, b ; Hardy et al., 1964) have suggested that denervation may cause a reductiono in the function of the transplant. Of three pos- 0 sible ways in which such a reduction could take place-namely, impairment of ventilation, perfuच sion, or diffusion-we wish to exclude impairment of perfusion. Our observations in this respect were्ष negative. We saw no significant changes inf? pulmonary flow which could be attributed too denervation. In fact we observed a direct con nexion between pulmonary flow and the way the transplant was handled. This was especially reles vant to atelectasis. 


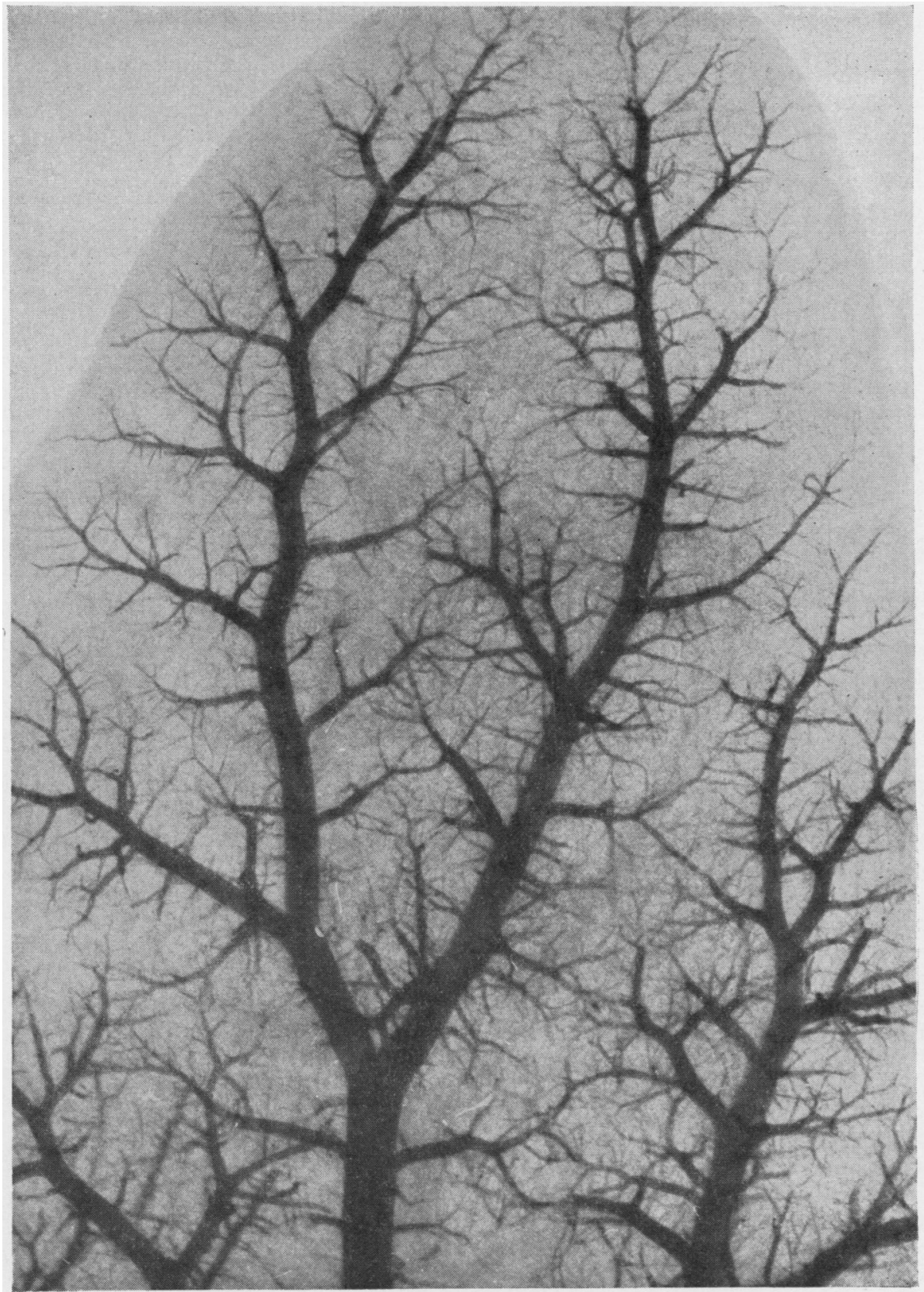

FIG. 12. Peripheral veins in the transplant, with partial occlusion of the venous anastomosis by thrombus, $\times 4$. Contrast medium injected distally in relation to thrombosed anastomosis. 
Comparing our results with the experiments on lung capillary circulation performed by Cournand (1947) and García Ramos (1955), we think that denervation of the transplanted lung does not influence its function directly. We think the importance of a vegetative nervous system in the lung concerns rather transfusion of stimuli to the breathing centre and regulation of the breathing cycle. This inference seems to be confirmed by experiments performed lately by Faber et al. (1965), which proved that even bilateral reimplantation (i.e., bilateral denervation) does not exclude survival.

\section{SUMMARY}

Twenty-four homologous lung transplantations were performed on dogs. The functional capacity of the transplanted lungs was established by angiography, measuring blood oxygen saturation, and microscopical observations of the blood flow in the lung tissue. All investigations were carried out directly after transplantation and during rethoracotomies. On the basis of these experiments the influence of lung denervation on its perfusion was excluded.

Three different ways of preparing the transplant were tried. The best results are to be expected after direct transplantation from animal to animal. If the lung has to be preserved for some time, the vascular bed should be thoroughly washed of blood with macrodex, and the lung should be kept inflated. Improper handling of the transplant may subsequently cause pulmonary congestion and haemorrhage.

All the dogs which died or were killed during experiments were submitted to necropsy and all the specimens were examined histologically and radiologically. Histological examinations showed that, in order to protect the bronchial mucosa of the transplant from sloughing, which may lead to infection, only a very short bronchial stump should be left with the transplant.

The surgical techniques we used may be considered satisfactory and could be used successfully in transplanting the human lung, provided that safe and reliable methods of suppressing the immunological reaction are found.

Our acknowledgements are due to Professor L. Manteuffel, Head of the Department of Thoracic and Cardiac Surgery, for enabling this work to be performed; to Professor S. Chodkowska, Head of the Pathology Department, and Professor K. Ossowska, Head of the Radiology Department of the Institute of Tuberculosis, for kind permission to carry out histological and radiological investigations in their departments.

We should also like to thank Dr. B. L. Chelstowska for anaesthetizing most of the animals for our experiments, Dr. J. Jaworski for the medical drawings, and all the junior staff who assisted at operations.

\section{REFERENCES}

Alican, F., and Hardy, J. D. (1963). Lung reimplantation. J. Amer med. Ass., 183, 849.

Blumenstock, D. A., Collins, J. A., Hechtman, H. B., Thomas, E. D., and Ferrebee, J. W. (1962). Functioning homografts of the lungs in dogs. Ann. N.Y. Acad. Sci., 99, 882 .

Lempert, N., and Morgado, F. (1965). Preservation of the canine lung in vitro for 24 hours with the use of hypothermia and hyperbaric oxygen. J. thorac. cardiovasc. Surg., 50, 769.

Borrie, J., and Lichter, L. (1964). Lung transplantation: technical problems. Thorax, 19, 383 .

Bücherl, E. S., Nasseri, M., and Prondzyński, B. von (1964a). Lung function studies after homotransplantation, autotransplantation, denervation of the left lung, and ligature of the right pulmonary artery. J. thorac. cardiovasc. Surg., 47, 455.

Eisele, R., Kirsch, U., Köhn, K., and Nasseri, M. (1964b). Veränderung der Toleranz für Lungentransplantationen durch Behandlung mit Methotrexate. Langenbecks Arch. klin. Chir., $305,282$.

Cournand, A. (1947). Recent observations on the dynamics of the pulmonary circulation. Bull. N.Y. Acad. Med., 23, 27.

Davies, L. G., Rosser, T. H. L., and West, L. R. (1965). Autotransplantation of the lung in sheep. Thorax, $20,481$.

de Bono, A. H. C., and Brock, R. (1964). Lung transplant. Brit. J. Surg., 51, 72 .

Demichow, W. P. (1963). Die experimentalle Transplantation lebenswichtiger Organe. Volk, Berlin.

Ellis, F. H. Grindley, J. H., and Edwards, J. E. (1951). The bronchial arteries. I. Experimental occlusion. Surgery, 30, 810.

Faber, L. P., Kenwell, J. M., and Beattie, E. J. (1961). Homologous lung transplantation. Arch. Surg., 83, 491.

- Pevsner, P. H., Pedreira, A. L. S., and Beattie, E. J. (1965). The immediate and long-term physiologic function of bilateral reimplanted lungs. J. thorac. cardiovasc. Surg., 50, 761.

Gago, O., Delgado, E., Archer, F. L., Shoenfeld, F. G., Ranniger, K., Nigro, S. L., and Adams, W. E. (1964). Homotransplantation and autotransplantation of a pulmonary lobe. Ibid., 48, 726. - Zajtchuk, R., Nigro, S. L., and Adams, W. E. (1965). Canine pulmonary homografts with uncontrolled cross-circulation. Ibid., $50,775$.

García Ramos, J. (1955). On the dynamics of the lung's capillary circulation. Amer. Rev. Tuberc., 71, 822 .

Hardin, C. A., and Kittle, C. F. (1954). Experiences with transplantation of the lung. Science, $119,97$.

Hardy, J. D., Eraslan, S., and Webb, W. R. (1964). Transplantation of the lung. Ann. Surg., 160, 440.

- Eraslan, S., Dalton, M. L., Alican, F., and Turner, M. D. (1963a). Reimplantation and homotransplantation of the lung. Ibid., 157, 707.

_ Webb, W. R., Dalton, M. L., and Walker, G. R. (1963b). Lung homotransplantation in man. J. Amer. med. Ass., 186, 1065.

Huggins, C. E. (1959). Reimplantation of lobes of the lung. Lancet, 2, 1059.

Juvenelle, A. A., Citret, C., Wiles, C. E., and Stewart, J. D. (1951). Pneumonectomy with replantation of the lung in the dog for physiologic study. J. thorac. Surg., 21, 111.

Magovern, G. J., and Yates, A. J. (1964). Human homotransplantation of left lung: report of a case. Ann. N.Y. Acad. Sci., 120, 710.

Neptune, W. B., Weller, R., and Bailey, C. P. (1953). Experimental lung transplantation. J. thorac. Surg., 26, 275.

Parsa P. Faber, L. P.. Staub, W. E., and Beattie, E. J. (1964). Experimental homotransplantation of the lungs with cytoxic agents. Dis. Chest, 45, 365.

Slim, M. S., Yacoubian, H. D., Wilson, J. L., Rubeiz, G. A., and Ghandur-Manymneh, L. (1964). Successful bilateral reimplantation of canine lungs. Surgery, 55, 676.

Thompson, D. (1964). A technique for bronchial anastomosis after resection of a portion of bronchus. Thorax, 19, 347.

Tobin, C. E. (1952). The bronchial arteries and their connections with other vessels in the human lung. Surg. Gynec. Obstet., 95, 741 .

Yeh, T. J., Ellison, L. T., and Ellison, R. G. (1962). Functional (D) evaluation of the autotransplanted lung in the dog. Amer. Rev. resp. Dis., 86, 791. 